\title{
COVID-19, sedentary behavior and dynapenic abdominal obesity in brazilian older people
}

\author{
André Bonadias Gadelha ib \\ Department of Physical Education and Sports, Federal Institute of Education, Science and Technology Goiano. Rodovia \\ Geraldo Silva Nascimento Km 2.5, Urutai - GO, 75790-000, Brazil, Phone +55 64993404092. \\ E-mail: andrebonadias@gmail.com
}

DOI: http://dx.doi.org/10.33837/msj.v3i1.1224

Received May 6, 2020. Accepted May 11, 2020

Associate editor: Anderson R da Silva

The novel coronavirus (COVID-19) epidemic has been caused by respiratory tract infectious disease which is motivated by a Severe Acute Respiratory Syndrome 2 (SARS-2), and has been recognized as a public health emergency by the World Health Organization (World Health Organization, 2020). In this scenario, COVID-19 was recently declared a global pandemic by the World Health Organization on 11th March 2020, being associated with substantial morbidity and mortality (Eurosurveillance Editorial Team, 2020).

Currently, medical records indicate that the pandemic has affected more than 200 countries around the world, with approximately 260,000 deaths until May 6th 2020. In Brazil, rate of deaths by COVID-19 has increased close to eight thousand people until the aforementioned date. Based on what is known, a group in imminent danger of contagion and even death by COVID-19 are the aged people ( $\geq 65$ years old). Noteworthy, eight out of ten deaths caused by COVID-19 reported in the US have been related to older adults. In Italy, aged people ( $\geq 85$ years old) infected by COVID-19 present case-fatality rate ranging from 15 to 20\% (Onder, Rezza, \& Brusaferro, 2020); additionally, in Brazil, according to Ministry of Health, approximately $80 \%$ of deaths by COVID-19 has been related to aged people. Therefore, policies that aimed to contain this pandemic have been adopted, especially for older adults, who are at imminent risk for SARS-2.

In general, the main preventive procedure to avoid contamination by COVID-19 include frequent and adequate hand sanitizing, covering the nose and mouth with a mask and social distancing (Lynch, Mahida, Oppenheim, \& Gray, 2020), being the latter

Copyright (C) The Author(s).

This is an open-access paper published by the Instituto Federal Goiano, Urutai - GO, Brazil. All rights reserved. It is distributed under the terms of the Creative Commons Attribution 4.0 International License. highly recommended for aged people. However, social distancing imposes more time at home, which might negatively influence the sedentary behavior. For example, spending more sitting time.

Briefly, this kind of sedentary behavior has been linked to increased risks of chronic conditions and even mortality, especially for older adults (Ekelund et al., 2016). Paradoxically, it has been recommended to aged people to keep physically active (Fragala et al., 2019) to avoid excess of fat accumulation, while losing both strength and functionality, which are phenotypes of obesity and dynapenia, respectively.

Obesity is consistently recognized as a relevant public health problem and can be easily monitored by waist circumference (abdominal obesity measure). The term dynapenia has been used to define the age-related loss of strength and functionality (Gadelha, Neri, Vainshelboim, Ferreira, \& Lima, 2019). Thus, the coexistence of abdominal obesity and dynapenia has introduced as dynapenic abdominal obesity (DAO) (Gadelha et al., 2019), and have been linked to falls (Gadelha et al., 2019), frailty, disability and even mortality (da Silva Alexandre, Scholes, Santos, de Oliveira Duarte, \& de Oliveira, 2018). It is known that inactivity (i.e., sedentary behavior) can favor traits of DAO. Therefore, attention in older adults during this worldwide pandemic must be given.

Home stay has been linked to both lower energy expenditure and muscle unloading, which provide excess of fat mass accumulation (Church \& Martin, 2018) and decline in muscle strength (Onder et al., 2020), respectively. Also, in this critical moment, inaccurate and often harmful "old person" stereotypes in combination with the social distancing have hinder actions to maintain physical and functional capacity of those people by honest valuing and care. In Brazil, appropriate places for physical activity remain closed due to the pandemic. Thus, while fearing the 
pandemic growth, sedentary behavior has been favored.

Regarding the sedentary behavior of aged people, honestly, I am afraid to believe that the panic displayed by part of society right now may be causing more harm than good. It is paradoxical like the "old saying of short blanket". Although there is no treatment for COVID-19, physical activity cannot be limited to the aforementioned places. Therefore, important questions should be considered in this regard: a) "how to stimulate waist circumference monitoring among older Brazilians during home stay?" and b) "how to promote strength training during this social distancing period?"

By this time, strategies and stand positions from geriatric entities and government are extremely necessary to meet the current need of physical activities. We cannot ignore the fact that sedentary behavior related to quarantine might be harmful to aged people. Therefore, this discussion should be considered for health promotion in Brazil.

\section{REFERENCES}

Church, T., \& Martin, C. K. (2018). The obesity epidemic: a consequence of reduced energy expenditure and the uncoupling of energy intake? Obesity, 26(1), 14-16.

da Silva Alexandre, T., Scholes, S., Santos, J. F., de Oliveira Duarte, Y. A., \& de Oliveira, C. (2018). Dynapenic abdominal obesity increases mortality risk among English and Brazilian older adults: a 10-year follow-up of the ELSA and SABE studies. The journal of nutrition, health $\mathcal{E}$ aging, 22(1), 138-144.

Ekelund, U., Steene-Johannessen, J., Brown, W. J., Fagerland, M. W., Owen, N., Powell, K. E., . . . Group, L. S. B. W. (2016). Does physical activity attenuate, or even eliminate, the detrimental association of sitting time with mortality? A harmonised metaanalysis of data from more than 1 million men and women. The Lancet, 388(10051), 1302-1310.

Eurosurveillance Editorial Team. (2020). Updated rapid risk assessment from ECDC on the novel coronavirus disease 2019 (COVID-19) pandemic: increased transmission in the EU/EEA and the UK. Eurosurveillance, 25(10).

Fragala, M. S., Cadore, E. L., Dorgo, S., Izquierdo, M., Kraemer, W. J., Peterson, M. D., \& Ryan, E. D. (2019). Resistance training for older adults: position statement from the National strength and conditioning association. The Journal of Strength $\mathcal{E}$ Conditioning Research, 33(8).

Gadelha, A. B., Neri, S. G., Vainshelboim, B., Ferreira, A. P., \& Lima, R. M. (2019). Dynapenic abdominal obesity and the incidence of falls in older women: a prospective study. Aging Clin Exp Res, 1-8.

Lynch, C., Mahida, N., Oppenheim, B., \& Gray, J. (2020). Washing our hands of the problem. Journal of Hospital Infection.

Onder, G., Rezza, G., \& Brusaferro, S. (2020). Case-fatality rate and characteristics of patients dying in relation to COVID-19 in Italy. Jama.

World Health Organization. (2020). Report of the WHO-China Joint Mission on coronavirus disease 2019 (COVID-19). 2020. World Health Organization: Geneva, Switzerland. Available at https://www. who. int/docs/default-source/coronaviruse/who-chinajointmission-on-covid-19-final-report. pdf. Accessed, 6.
To cite this paper:

Gadelha, A. B. (2020). COVID-19, sedentary behavior and dynapenic abdominal obesity in brazilian older people. Multi-Science Journal, 3(1): 30-31. DOI: http://dx.doi.org/10.33837/msj.v3i1.1224 